\title{
Pembuatan Motion Graphics Untuk Media Training Komunikasi Efektif Budaya Horenso Di PT Amerta Indah Otsuka
}

\section{(Creation Of Motion Graphics For Media Training Effective Communication Horenso Culture In PT Amerta Indah Otsuka)}

\author{
Febi Walmika Saragih ${ }^{1}$, Maria Susan Anggreainy ${ }^{2}$, Reza Kusuma Putra \\ ${ }^{1}$ Sekolah Vokasi Institut Pertanian Bogor, Jl Kumbang No. 14, Kota Bogor \\ ${ }^{2}$ Sekolah Vokasi Institut Pertanian Bogor, Jl Kumbang No. 14, Kota Bogor \\ ${ }^{3} \mathrm{PT}$ Amerta Indah Otsuka, JI Raya Siliwangi No. KM. 28, Kutajaya, Sukabumi \\ Email : febiwalmika@gmail.com, susan.anggreainy@gmail.com, \\ azer.tea@gmail.com
}

\section{ABSTRACT}

PT Amerta Indah Otsuka is a company engaged in manufacturing, nutrition and pharmaceuticals. It company has many employees and is devided into several departement, because of that, effective communication is needed.

HORENSO is an acronym from Japanese language, that is hokoku, renraku and sodan. HORENSO in Indonesia language thai is report, information and consult. HORENSO culture is considered as one of the keys to success in a corporate organization in Japan, because it's more important the process and cooperation to reach the goal. At the appointed time, HCD Departement routine remindes employees for training HORENSO culture.

Training about effective communication is carried out by speaker within two hours. Material submitted using video that is not good quality, therefore HCD Departement want to create a motion graphics that summarizes all the footage from the previous video, so that is can be delivered informatively to increase employee attention to the importance of effective communication in the corporate environment.

Keywords : HORENSO,effective communication, motion graphics, training

\section{ABSTRAK}

PT Amerta Indah Otsuka merupakan perusahaan yang bergerak dalam bidang manufaktur nutrisi dan farmasi. Perusahaan ini memiliki banyak karyawan yang dibagi dalam beberapa departemen, dengan banyaknya karyawan tersebut maka diperlukan komunikasi yang efektif karyawan antar departemen.

HORENSO adalah suatu akronim dari bahasa Jepang yang dibentuk dari tiga kata, yaitu hokoku, renraku dan sodan. Dalam Bahasa Indonesia dapat diartikan laporan, informasi dan konsultasi. Budaya HORENSO ini dianggap sebagai salah satu kunci sukses dalam suatu organisasi perusahaan di Jepang, karena sangat memperhatikan proses untuk 
mencapai target dan menitikberatkan pada kerjasama antar Departemen. Pada tanggal dan waktu yang telah ditentukan, Departemen HCD dengan rutin mengingatkan karyawan untuk mengikuti training komunikasi efektif budaya HORENSO.

Training komunikasi efektif dilaksanakan oleh pembicara dalam waktu dua jam dengan materi yang dipaparkan menggunakan cuplikan video yang kualitasnya kurang baik, dengan keadaan video yang sudah ada sebelumnya Departemen HCD ingin membuat sebuah motion graphics yang merangkum semua cuplikan dari video yang ada, sehingga materi dapat tersampaikan dengan infomatif untuk meningkatkan perhatian karyawan terhadap pentingnya komunikasi yang efektif di lingkungan organisasi perusahaan.

Kata Kunci : HORENSO, komunikasi efektif, motion graphics, training

\section{PENDAHULUAN}

Komunikasi adalah proses penyampaian pesan oleh seseorang kepada orang lain untuk memberitahu, mengubah sikap, pendapat, atau perilaku, baik secara lisan (langsung) ataupun melalui media (tidak langsung) (Effendy 2014). Permasalahan yang sering timbul di suatu organisasi perusahaan yaitu lemahnya komunikasi dalam kerja sama antar tim atau kurangnya komunikasi antara atasan dengan karyawan. Seperti halnya yang sering terjadi, banyak laporan yang baru di follow up kepada atasan setelah diingatkan beberapa kali dan tidak adanya progress dari tugas-tugas yang diberikan.

Berdasarkan penjelasan mengenai lemahnya komunikasi yang terjadi pada organisasi perusahaan pada saat ini, Departemen Housing \& Community Development (HCD) di PT Amerta Indah Otsuka setiap waktunya dengan rutin mengadakan training terhadap karyawan lama untuk menghindari komunikasi yang kurang efektif. Training tersebut tidak hanya untuk karyawan lama, melainkan bagi karyawan baru pun training komunikasi efektif harus dilakukan.

Dapat dibayangkan betapa disayangkan apabila pencapaian sasaran kerja tidak tercapai atau bahkan gagal dikarenakan kurangnya komunikasi antar tim. Padahal di saat ini, teknologi informasi dan komunikasi sudah semakin canggih. Sebelum perkembangan teknologi informasi dan komunikasi seperti saat ini, sudah banyak perusahaan Jepang yang telah menerapkan budaya HORENSO agar komunikasi berjalan secara efektif.

HORENSO adalah suatu akronim dari bahasa Jepang yang dibentuk dari tiga kata, yaitu hokoku, renraku dan sodan. Dalam bahasa Inggris, kata-kata tersebut diterjemahkan menjadi report, contact atau information, dan consult. Jadi, dalam bahasa Indonesia dapat diartikan laporan, informasi dan konsultasi. HORENSO diciptakan dan dipergunakan pertama 
kali di lingkungan perusahaan di Jepang. Tujuannya adalah untuk menciptakan lingkungan kerja dengan segala informasi agar tersampaikan secara cepat dan tepat. Serta setiap kemajuan suatu aktivitas bisa diketahui oleh banyak orang, karena adanya laporan yang intens. "Sampai saat ini hampir seluruh pabrik Jepang masih menerapkan prinsip tersebut termasuk di Indonesia" (Cisca 2008).

Budaya HORENSO ini dianggap sebagai salah satu kunci sukses dalam suatu organisasi perusahaan di Jepang, karena perusahaan Jepang sangat memperhatikan tahapan proses untuk mencapai target dan menitikberatkan pada kerjasama antar tim atau Departemen.

Departemen HCD telah mengaplikasikan training komunikasi efektif budaya HORENSO melalui presentasi menggunakan video yang memiliki kualitas rendah dan belum menggunakan tahap editing video. Oleh karena itu menurut Assistant Manager of HCD, setidaknya HCD membutuhkan motion graphics yang lebih up to date untuk salah satu media training untuk karyawan baru atau karyawan lama pada materi komunikasi efektif.

Berdasarkan berbagai hal yang telah dijelaskan diatas, maka judul yang dipilih untuk tugas akhir ini adalah "Pembuatan Motion Graphics untuk Media Training Komunikasi Efektif Budaya HORENSO di PT Amerta Indah Otsuka". Tujuan dari Pembuatan Motion Graphics untuk Media Training Komunikasi Efektif Budaya HORENSO di PT Amerta Indah Otsuka adalah menghasilkan produk motion grapohics yang informatif.

\section{METODE PENELITIAN}

Dalam proses Pembuatan Motion Graphics untuk Media Training Komunikasi Efektif Budaya HORENSO di PT Amerta Indah Otsuka ini memiliki delapan tahapan yaitu perancangan konsep, pencarian referensi, pembuatan naskah dan storyboard, material collecting, pembuatan project, revisi dan konsultasi, editing tahap akhir dan distribusi. Tahap pembuatan motion graphics dapat dilihat pada Gambar 1.

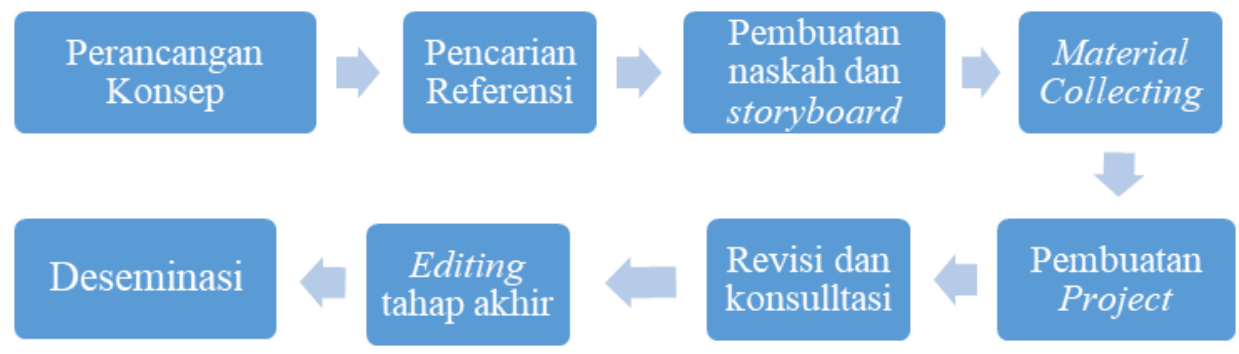

Febi Walmika Saragih, Maria Susan Anggreainy, Reza Kusuma Putra 


\section{Perancangan Konsep}

Perancangan konsep digunakan untuk mengetahui detail project motion graphics yang akan dibuat sesuai dengan tujuan pembuatan motion graphics. Pada tahapan ini mendeskripsikan judul, target audience, durasi, audio, dan model animasi.

2. Pencarian Referensi

Tahapan ini

dilakukan untuk mencari referensi terkait teks, seni, gambar, suara, animasi, transisi dan video sebagai acuan dalam pembuatan motion graphics. Menurut KBBI referensi adalah sumber acuan (rujukan, petunjuk). Pencarian referensi dalam pembuatan motion graphics ini melalui internet, buku dan informasi dari Departemen Housing \& Development dan Departemen IT.

\section{Pembuatan Naskah (Script) dan Storyboard}

Pembuatan naskah digunakan untuk pedoman dalam pembuatan storyboard. Project motion graphics ini menggunakan storyboard untuk menggambarkan alur cerita secara detail. Storyboard adalah sederetan ilustrasi atau gambar yang ditampilkan secara berurutan untuk keperluan visualisasi awal dari suatu file, animasi, atau urutan media interaktif (Binanto 2010).

\section{Material Collecting}

Material Collecting adalah tahap pengumpulan bahan yang sesuai dengan kebutuhan yang dikerjakan. Bahan-bahan tersebut antara lain gambar, audio, animasi, dan lain-lain yang diperlukan pada tahap berikutnya (Binanto 2010). Bahan yang diperlukan dalam pembuatan motion graphics ini dapat diperoleh dari sumber-sumber yang bersangkutan.

\section{Pembuatan Project}

Project ini dibuat berdasarkan konsep yang telah dirancang dan bahan- bahan yang telah dikumpulkan. Terdapat beberapa tahapan dalam pembuatan project ini, yaitu modelling dan texturing, animating, rendering 1, dubbing, sound editing, compositing, editing dan rendering 2 .

\section{Revisi dan Konsultasi}

Revisi dan konsultasi dilakukan dengan Departemen HCD terkait project motion graphics yang telah diselesaikan. Konsultasi dilakukan untuk meninjau kembali project motion graphics yang telah dihasilkan. Jika project motion graphics sudah layak, maka pihak Departemen HCD langsung 
mendistribusikan project motion graphics tersebut. Sedangkan jika terdapat revisi terhadap project motion graphics yang telah dihasilkan, maka dilanjutkan ke tahap editing tahap akhir. Menurut KBBI revisi adalah peninjauan (pemerikasaan) kembali untuk melakukan perbaikan. Menurut $\mathrm{KBBI}$ konsultasi adalah pertukaran pikiran untuk mendapatkan suatu kesimpulan.

\section{Editing Tahap Akhir}

Editing tahap akhir dilakukan setelah project motion graphics sebelumnya telah direvisi dan meninjau kembali kekurangan apa saja yang terdapat dalam project motion graphics tersebut.

\section{Deseminasi}

Tahapan deseminasi merupakan kegiatan final dalam pengembangan media yang sudah siap untuk digunakan dalam kegiatan. Langkah ini diawali dengan menentukan saluran yang digunakan untuk mendistribusikan media yang digunakan, apakah dengan melakukan konversi menjadi format yang mendukung untuk disimpan di dalam Compact Disc (CD), flashdrive, atau dengan melakukan penyimpanan dengan media Cloud (Suryani et al. 2018). Desiminasi ini dilakukan oleh pihak perusahaan melalui training terhadap karyawan PT Amerta Indah Otsuka oleh Departemen HCD.

\section{HASIL DAN PEMBAHASAN}

Pada bab ini, penulis akan membahas secara detail mengenai tahapan pembuatan motion graphics yang diimplementasikan dengan menerapkan metode yang di jelaskan dalam bab sebelumnya. Terdapat 8 (delapan) tahapan dalam pembuatan motion graphics, diantaranya perancangan konsep, pencarian referensi, pembuatan naskah dan storyboard, material collecting, pembuatan project, revisi dan konsultasi, editing tahap akhir dan deseminasi.

\section{Perancangan Konsep}

Perancangan konsep merupakan tahapan awal dalam pembuatan motion graphics. Pada tahapan ini dilakukan untuk menentukan bagaimana bentuk visual dari video yang akan dibuat. Konsep ini pun akan menetukan tujuan dan target audience serta hasil yang diperoleh. Video ini akan memiliki durasi kurang lebih lima menit dan dibuat dalam bentuk motion graphics.

Perancangan konsep mendeskripsikan judul, audience, durasi, audio, dan animasi. Hasil deskripsi perancangan konsep pembuatan motion graphics dapat dilihat pada Tabel 1. 
Tabel 1 Perancangan Konsep

\begin{tabular}{|c|c|}
\hline Judul & $\begin{array}{l}\text { Pembuatan Motion graphics untuk Media Training } \\
\text { : Komunikasi Efektif Budaya HORENSO di PT Amerta Indah } \\
\text { Otsuka. }\end{array}$ \\
\hline Audience & $\begin{array}{l}\text { Kepala Departemen, Kepala Divisi serta seluruh staff } \\
\text { karyawan PT Amerta Indah Otsuka. }\end{array}$ \\
\hline Durasi & $: \pm 5 r$ \\
\hline Audio & : Sound effect, voice over, dan backsound. \\
\hline Animasi & $\begin{array}{l}\text { - Animasi menggunakan model 2D } \\
\text { - Video menggunakan efek transisi dan zoom in/out dan } \\
\text { effect transisi lainnya. } \\
\text { - Efek animasi 2D pada video menggunakan cara manual. }\end{array}$ \\
\hline
\end{tabular}

2. Pencarian Referensi

Penulis mencari referensi untuk pembuatan motion graphics ini melalui beberapa website. Selain itu untuk informasi mengenai informasi tentang HORENSO didapatkan dari pembimbing lapang dan dari beberapa artikel. Tujuan dari pencarian referensi yaitu untuk mempermudah penulis dalam melakukan pembuatan motion graphics. Referensi video tersebut dapat dicari pada youtube, sedangkan untuk pencarian gambar penulis mencari pada website freepik.com, untuk font didapat dari website daFont.com, serta untuk menyesuaikan warna agar terlihat menarik penulis mencari referensi dari website colorpallet.com.

\section{Pembuatan naskah dan Storyboard}

Setelah mendapatkan referensi berdasarkan konsep yang telah ditentukan, kemudian masuk ke tahap pembuatan naskah (script) untuk dijadikan pedoman dalam tahapan pembuatan project. Tujuannya yaitu agar terwujudnya konsistensi cerita yang telah dirancang. Detail naskah yang dibuat terdapat pada Lampiran 1.

Setelah pembuatan naskah selesai, maka dilanjutkan dengan pembuatan storyboard. Pembuatan storyboard dibutuhkan sebagai acuan dari scene yang akan dibuat nantinya dalam tahap pembuatan project, sehingga tidak terjadi penyimpangan terhadap ide cerita.

\section{Material Collecting}

Material collecting merupakan tahapan yang harus dipersipkan sebelum memulai tahap pembuatan project. Pada tahapan ini penulis harus mengumpulkan semua data-data yang dibutuhkan dalam pembuatan motion graphics ini. Tabel Assets Material Collecting dapat dilihat pada Tabel 2.

\section{Tabel 2 Daftar Assets Material Collecting}




\begin{tabular}{|c|c|c|c|}
\hline No & Material & File & Source \\
\hline 1 & $\begin{array}{l}\text { Logo PT Amerta } \\
\text { Indah Otsuka }\end{array}$ & $\begin{array}{l}\text { Otsuka } \\
\text { PT. Amerta Indah Otsuka }\end{array}$ & PT Amerta Indah Otsuka \\
\hline 2 & Backsound & $\begin{array}{l}\text { bensound-retros } \\
\text { oul }\end{array}$ & $\begin{array}{l}\text { Departemen IT PT Amerta } \\
\text { Indah Otsuka dan } \\
\text { https://www.bensound.com }\end{array}$ \\
\hline 3 & Color Palletes & $\begin{array}{l}\text { ChartsBlue Color } \\
\text { Palette- } \\
\text { color-hex.com }\end{array}$ & $\begin{array}{l}\text { https://www.color- } \\
\text { hex.com/color-palettes/ }\end{array}$ \\
\hline 4 & Vector & $\underset{70}{A i}$ & https://www.freepik.com/ \\
\hline 5 & Font & $\begin{array}{c}\text { Aby } \\
\text { Sweet Rathulia }\end{array}$ & https://www.daFont.com/ \\
\hline 6 & $\begin{array}{l}\text { Suara Latar } \\
\text { (voice over) }\end{array}$ & Mp3 & $\begin{array}{l}\text { - Merekam suara dari Febi } \\
\text { Walmika Saragih } \\
\text { - Merekam suara atasan } \\
\text { dari Bapak Jasamen } \\
\text { - Merekam suara client dari } \\
\text { Wilson } \\
\text { - Merekam suara karyawan } \\
\text { Okabayashi } \\
\text { - dari Dimas }\end{array}$ \\
\hline
\end{tabular}

\section{Pembuatan Project}

Tahap pembuatan project merupakan implementasi dari storyboard yang telah dirancang. Dalam proses pembuatan motion graphics ini dibutuhkan spesifikasi perangkat keras (hardware) dan perangkat lunak (software) yang dapat mendukung proses pembuatan motion graphics ini dengan baik.

Setelah menyiapkan peralatan perangkat keras (hardware) dan 
perangkat lunak (software) untuk kebutuhan pengerjaan project, maka pembuatan project dapat dilaksanakan sesuai dengan storyboard yang telah dirancang sebelumnya. Pada tahap pembuatan project meliputi Modelling (Penggambaran) dan Texturing (pewarnaan), Animating, Rendering 1, Dubbing, sound editing (Editing suara), Compositing, Editing, dan Rendering 2.

\section{a. Modelling dan Texturing}

Proses ini adalah proses pembuatan model objek dalam bentuk 2D, model pada motion graphics ini berupa karakter seperti manusia, tumbuhan dan lainnya. Model harus dibuat dengan detail dan sesuai dengan ukuran dan skala pada sketsa desain yang telah ditentukan sebelumnya, sehingga objek model akan tampak ideal dan proporsional untuk dilihat. Setelah dilakukan proses modelling, nantinya objek tersebut dilanjutkan ketahap pemberian warna material (texturing) sehingga akan tampak terkesan nyata. Contoh gambar yang telah melalui tahapan modelling dan texturing menggunakan software Adobe Illustrator dapat dilihat pada Gambar 2.

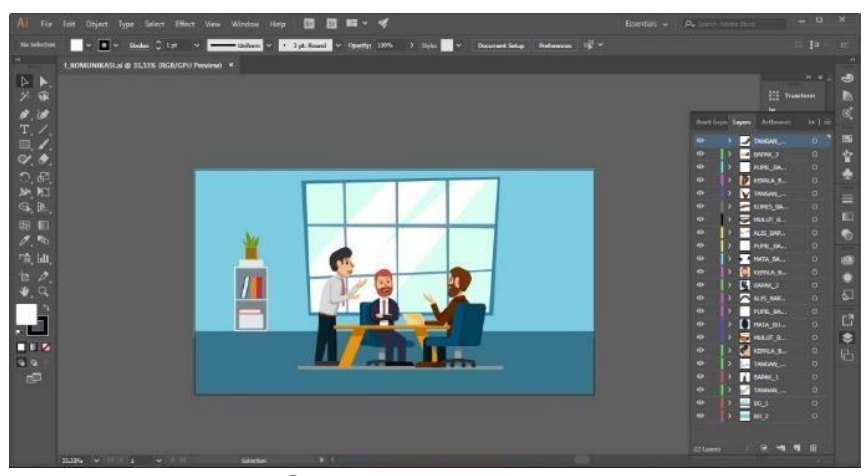

Gambar 2 Modelling

Setelah semua objek yang dibutuhkan terkumpul sesuai scene pada storyboard, untuk dapat melanjutkan ketahap animating maka terlebih dahulu dilakukan pemisahan layer sesuai objek yang akan digerakkan atau dianimasikan. Contohnya jika akan menganimasikan objek manusia berjalan, maka layer yang harus dipisahkan yaitu kaki kanan dan kiri. Proses pengerjaan dapat dilihat pada Gambar 3.

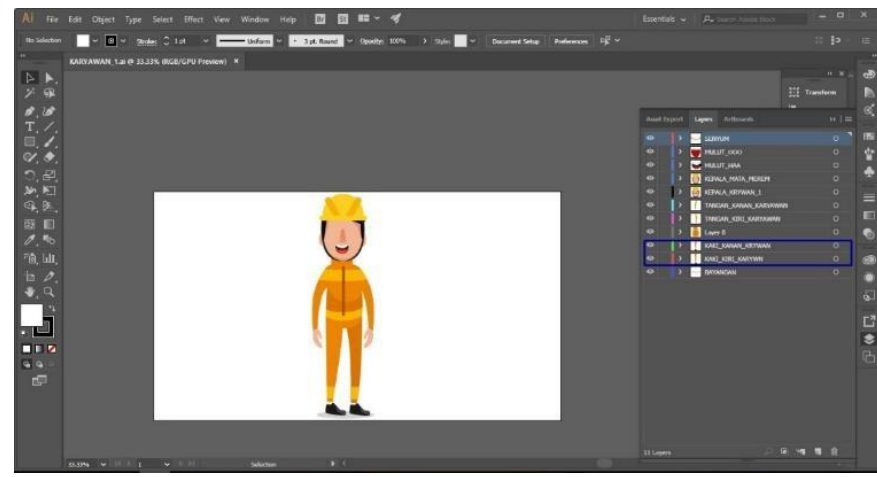

Gambar 3 Pemisahan Layer dalam Sofware Adobe Illustrator CC 
Jika pada objek tubuh manusia akan digerakkan secara keseluruhan. Maka pemisahan layer dapat dilakukan sesuai kebutuhan penganimasian. Setelah proses pemisahan layer telah selesai, maka dapat dilanjutkan ketahap animating.

b. Animating

Tahap animating merupakan tahapan dimana file objek yang telah dibuat kemudian digabungkan untuk dianimasikan atau digerakkan dalam bentuk video scene, baik itu gerakan objek untuk menciptakan animasi walkt grought, animasi fly throught dan lainnya. Proses penganimasian ini menggunakan software Adobe After Effects CC. Pada proses ini dapat ditentukan arah dimulainya suatu gerakan animasi, disesuaikan dengan storyboard yang telah dibuat pada tahap pembuatan naskah dan storyboard.

Setelah proses pemisahan layer selesai, kemudian masuk ketahap proses animating, yaitu proses menggerakkan objek. Langkah pertama yaitu, drag file objek pada software After Effcts CC. Setelah itu akan muncul seperti Gambar 4.

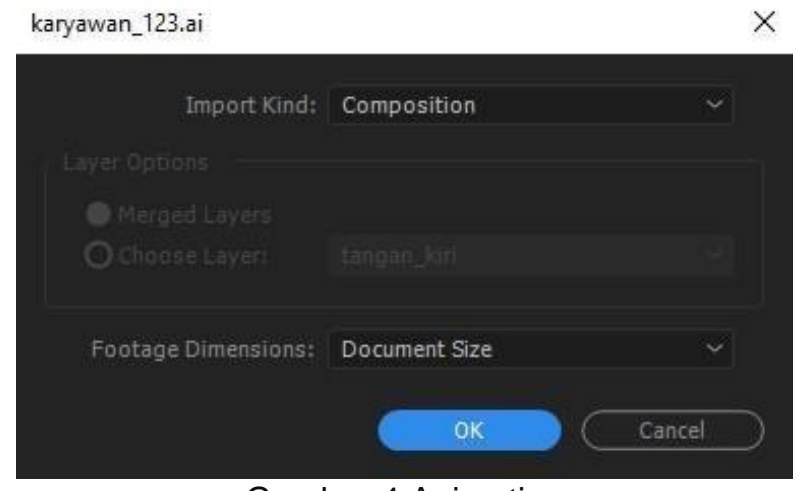

Gambar 4 Animating

Ketika muncul seperti Gambar 17, maka pilihlah composition pada Import Kind, agar layer yang telah dipisahkan pada Adobe Illustrator dapat terdeteksi. Jika memilih composition, maka secara otomatis layer options akan terkunci dan membuat sebuah composition baru di Adobe After Effect yang isinya layer-layer yang telah dipisahkan pada Adobe Illustrator. Composition merupakan panel yang digunakan sebagai "layar TV" untuk melihat hasil editing dan pembuatan video (Enterprise 2018). Setelah terbentuk composition, proses penganimasian dapat dilakukan. Kemudian pada footage Dimensions pilih Document Size agar ukuran file sama seperti ukuran awal di Adobe Illustrator.

Setelah file terbuka pada software Adobe After Effect, maka gunakan tool Pupet Pin Tool. Fokuskan pada layer kaki kanan dan kiri untuk menggerakkannya. Kemudian berikan titik tumpu menggunakan Puppet Pin 
Tool $($ Ctrl $+\mathrm{P})$ pada bagian-bagian tertentu agar pergerakkan kaki terlihat seperti berjalan. Proses pengerjaan dapat dilihat pada Gambar 5.

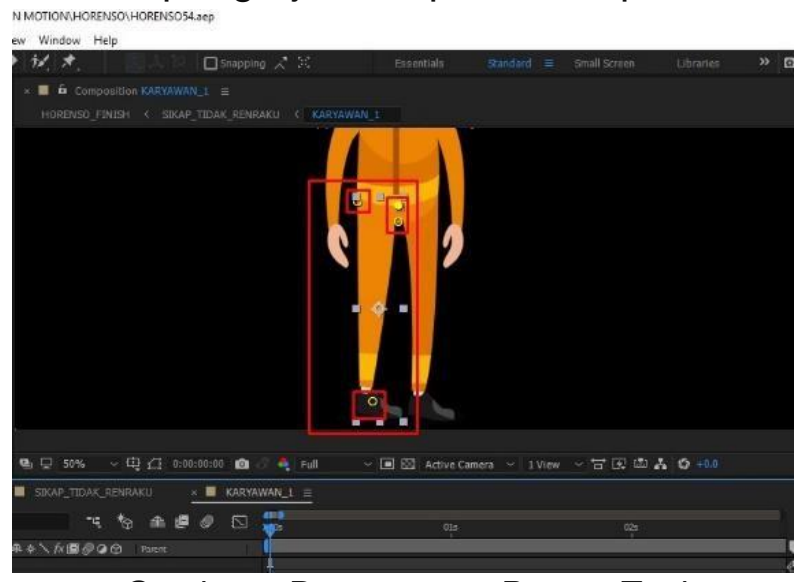

Gambar 5 Penggunaan Puppet Tool

Pada saat memberikan titik tumpu, pastikan Current Time Indicator diletakkan diawal atau dapat disesuaikan sesuai kebutuhan seperti yang terlihat pada Gambar 6.

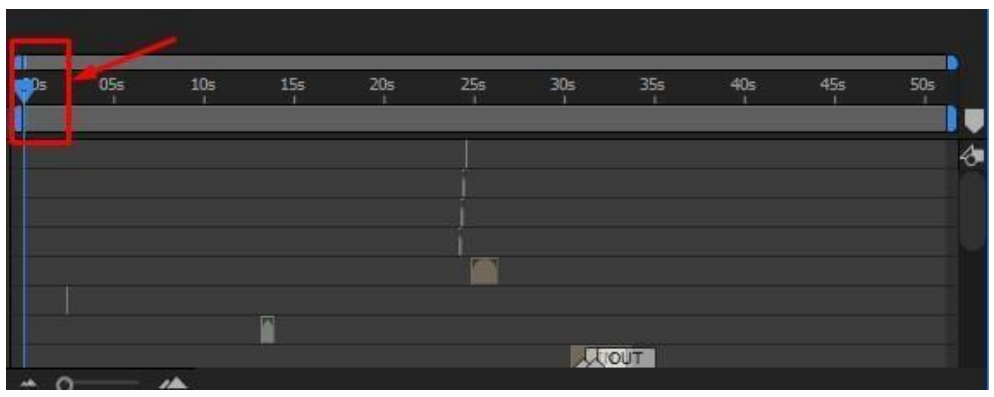

Gambar 6 Current Time Indicator

Selanjutnya titik tumpu dapat dipindah posisi sesuai gerakkan yang diinginkan. Saat memindahkan titik tumpu, pastikan current Time Indicator pun dipindahkan dari posisi awal agar pergerakan objek terlihat.

\section{c. Rendering 1}

Menurut buku yang berjudul "Adobe After Effects Komplet" Rendering adalah proses dimana Adobe After Effects memproses footage atau video sehingga menghasilkan preview (tampilan) yang diharapkan. Buku ini juga mengatakan render adalah proses untuk menjadikan video hasil editing itu menjadi file movie yang siap ditonton atau upload (misalnya ke Youtube) (Enterprise 2018).

Proses ini adalah proses pengkalkulasian pada model 2D yang telah diberi texture dan animation. Dengan demikian, hasil animasi yang didapatkan tampak sangat nyata dan menarik. Pada proses rendering, penulis menggunakan bantuan software Adobe Media Encoder CC, karena pada software Adobe After Effects CC yang digunakan oleh penulis tidak terdapat format ( $\left.{ }^{*} \mathrm{mp} 4\right)$. Proses rendering 1 dapat dilihat pada Gambar 7. 


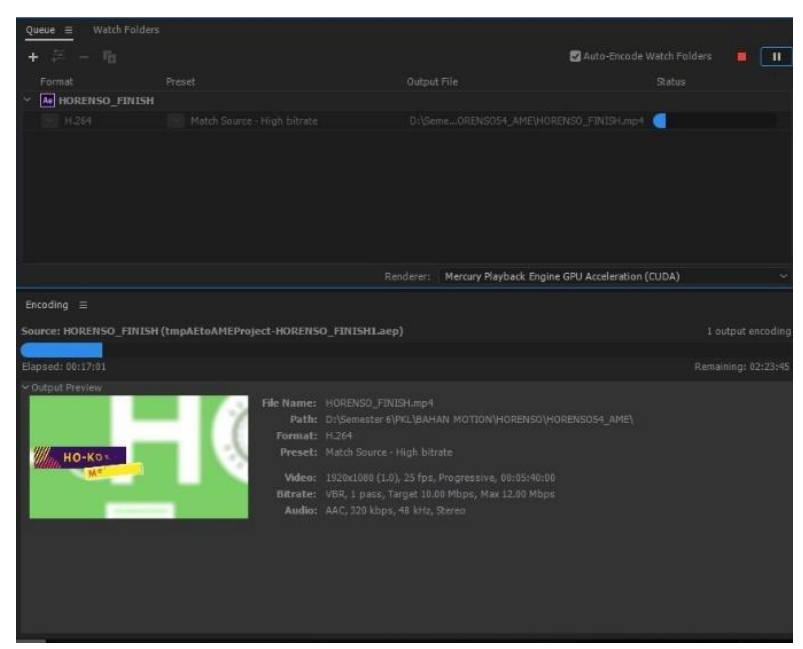

Gambar 7 Rendering 1

\section{d. Dubbing (Perekaman Suara)}

Dubbing (perekaman suara) merupakan tahapan merekam suara untuk pemberian voice over (suara latar) pada motion graphics ini. Dimana suara yang digunakan tersebut akan dimasukkan kedalam video sebagai penjelas untuk mengartikan video tersebut.

Dalam proses dubbing (perekaman suara) menggunakan perangkat sound record seperti handphone Oppo F9 dengan memakai suara latar dari Febi Walmika Saragih, Bapak Jasamen untuk suara latar atasan, Wilson untuk suara latar Client, dan Dimas untuk suara latar Okabayashi.

\section{e. Sound Editing}

Proses sound editing merupakan editing suara yang telah direkam sebelumnya menggunakan software Adobe Audition CC dan Audacity untuk dibersihkan dari noise dan juga digunakan sebagai proses pemotongan suara yang akan dimasukkan kedalam motion graphics ini. Pengaturan sound editing pada Adobe Audition CC dan Audacity untuk menghilangkan noise dapat dilihat pada Gambar 8 dan Gambar 9.

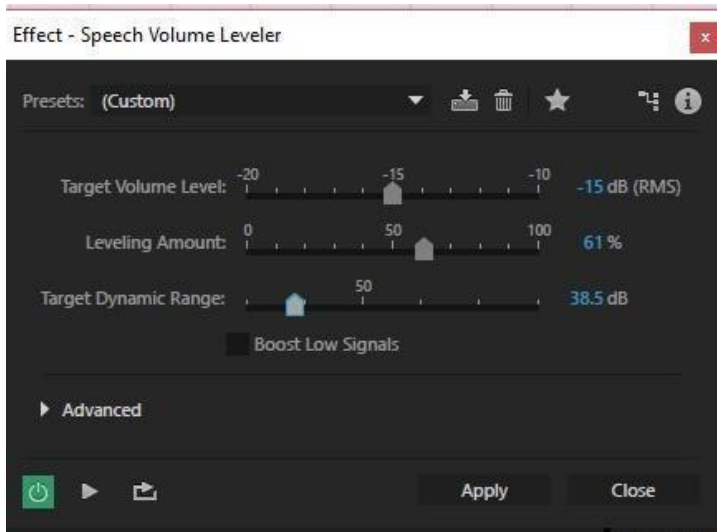

Gambar 8 Sound Editing menggunakan Adobe Audition CC 
Pada pengaturan sound editing tersebut, dipilih preset yaitu custom agar pengaturan Target Volume Level, Levelling Amount dan Target Dynamic Range dapat diatur secara manual. Setelah itu, hasil pengaturan dapat didengarkan terlebih dahulu dengan klik segitiga yang berada pada pojok kiri bawah. Setelah terdengar baik, maka dapat dilanjutkan menggunakan software Audacity untuk mengatur kembali kejernihan suara. Pengaturan yang menggunakan Audacity dapat dilihat pada Gambar 9. Tetapi, jika suara terdengar sudah cukup baik, maka dapat hanya menggunakan Adobe Audition saja.

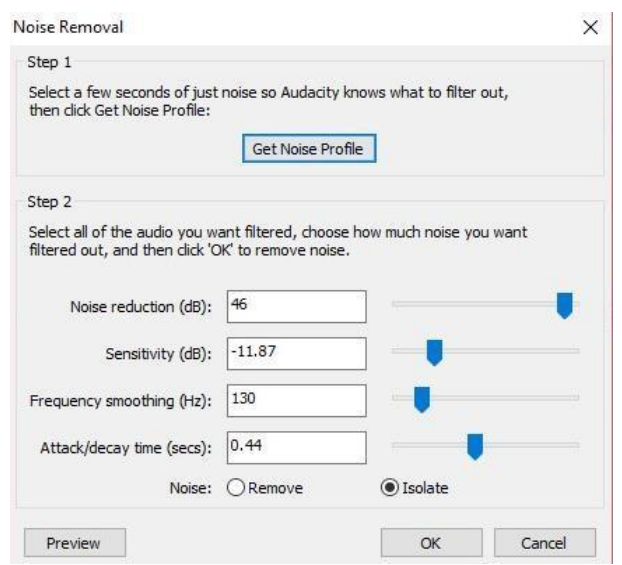

Gambar 9 Sound Editing menggunakan Audacity

\section{f. Compositing Visual Effect}

Tahap compositing adalah tahapan pembuatan intro atau penambahan efek-efek visual yang dapat memperindah tampilan animasi, seperti pemberian efek cahaya, ledakan, ataupun yang lainya.

\section{g. Editing (Preview \& Final)}

Pada tahap editing ini, penulis menggunakan software Adobe Premiere Pro CC. Proses editing ini berfungsi untuk menggabungkan semua file yang telah dibuat dari perekaman suara sampai proses penganimasian objek dan pemberian voice over serta backsound untuk memberikan kesan menarik dan hidup pada sebuah video. Tampilan proses editing dapat dilihat pada Gambar 10.

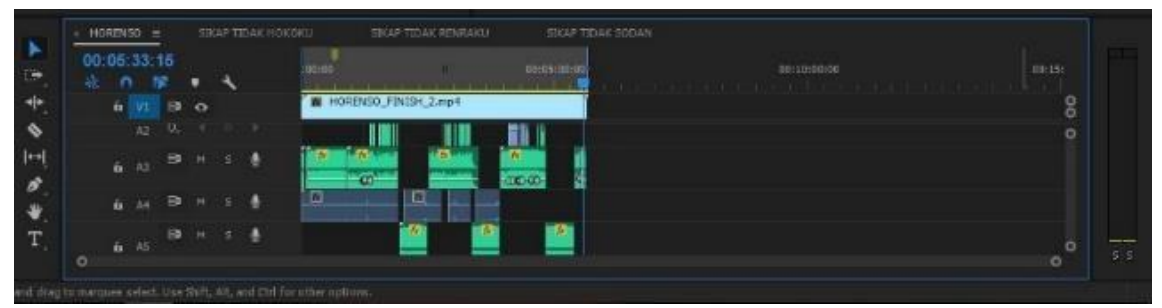

Gambar 10 Editing 


\section{h. Rendering 2}

Proses akhir dari pembuatan motion graphics ini adalah rendering, sama halnya dengan proses rendering di After Effects CC sebelumnya. Namun, jika pada software Adobe After Effects tidak ada pilihan format H.264, untuk melanjutkan proses rendering agar formatnya tetap H.264. Maka dapat dilakukan dengan bantuan software tambahan yaitu Adobe Media Encoder CC.

Proses rendering pada Adobe Premiere Pro CC ialah untuk membuat potongan-potongan video dan suara menjadi satu bentuk file yang utuh. Dalam proses rendering banyak cara yang dilakukan untuk me-render, salah satunya dengan menekan tombol $\mathrm{Ctrl}+\mathrm{M}$, kemudian pilih format H.264 ('mp4) setelah itu sesuaikan preset seperti yang diinginkan.

\section{Revisi dan Konsultasi}

Revisi dilakukan setelah produk motion graphics telah selesai rendering 2, kemudian diberikan kepada Departemen HCD PT Amerta Indah Otsuka untuk dilakukan review kembali dan menerima berbagai masukkan dari staff Departemen HCD dan kekurangan apa saja dalam motion grpahics, meliputi vector dan warna, pemilihan Font, pemilihan backsound dan sound effect, serta informasi yang disampaikan.

\section{Editing Tahap Akhir}

Editing tahap akhir dilakukan setelah penulis mendapatkan berbagai masukan dari pihak perusahaan dan staf Departemen HCD. Kemudian menambahkan hal yang kurang di dalam motion graphics yang telah dibuat sebelumnya.

\section{Deseminasi}

Tahap deseminasi merupakan tahapan dimana produk yang sudah dibuat akan digunakan oleh pengguna akhir. Setelah melakukan tahap revisi \& konsultasi ataupun Editing tahap akhir, produk multimedia dikemas dan didistribusikan dalam bentuk diantaranya flashdisk, harddisk, dan compact disk (CD) dengan hasil akhir produksi adalah sebuah file dengan format $\left({ }^{*} \mathrm{mp} 4\right)$ dan dapat diputar di media komuputer.

\section{SIMPULAN}

Pembuatan motion graphics ini dibuat berdasarkan kebutuhan pihak Departemen HCD untuk media training komunikasi efektif budaya HORENSO dan diperuntukan bagi karyawan PT Amerta Indah Otsuka. Semua permasalahan mengenai media training komunikasi efektif yang di selenggarakan oleh Departemen HCD di PT Amerta Indah Otsuka dapat diselesaikan dengan menghasilkan motion graphics yang telah berhasil 
dibuat selama mengikuti Praktik Kerja Lapangan (PKL) di PT AMerta Indah Otsuka. Motion graphics yang sudah dibuat selanjutnya di berikan kepada pihak Departemen HCD PT Amerta Indah Otsuka untuk dilakukan distribusi melalui training.

\section{SARAN}

Pembuatan motion graphics ini masih memiliki beberapa kekurangan sehingga perlu adanya sedikit perbaikan dan pengembangan lebih lanjut. Proses editing selanjutnya diharapkan dapat lebih baik lagi dalam segi pemberian efek dan pembuatan gambar, karena gambar yang digunakan beberapa mengambil dari website situs freepik sehingga banyak infografis hasil karya orang lain yang menggunakan gambar yang sama.

\section{DAFTAR PUSTAKA}

Binanto I. 2010. Multimedia Digita/_Dasar Teori dan Pengembangannya. Nikodemus WK, editor.Yogyakarta (ID) : Penerbit Andi. Tersedia pada https://books.google.co.id/books/about/Multimedia_Digital_Dasar_Te ori_da n_Penge.html?id=UqWLna0oaUYC

Cisca. 2008. HORENSO. [internet]. [diakses 2019 Februari 23]. Tersedia pada : https://simpleqs.wordpress.com/2008/08/28/HORENSO/

Design I. 2014 Mei 21. Belajar Dasar-Dasar Adobe After Effects. [internet]. [diakses 2019 Februari 2019]. Tersedia pada : http://www.idseducation.com/

http://www.idseducation.com/articles/belajar-dasar-dasar-adobeaftereffect/

Effendy O. 2014. Definisi Komunikasi Menurut Para Ahli. [internet]. [diakses 2019 Februari 22]. Tersedia pada https://www.komunikasipraktis.com/2014/10/daftar-definisikomunikasimenurut-para-ahli.html

Enterprise J. 2018. Adobe After Effects Komplet. Yogyakarta (ID) : PT Elex Media Komputindo.

Gamble T K, Gamble M . 2013. Communicarion Works. New York : McGraw-Hill Education.

Suryani N, Setiawan A, Putria A. 2018. Media Pembelajaran Inovatif dan Pengembangannya. Latifah $\mathrm{P}$, editor. Bandung (ID) :ROSDA. 